\title{
Reflexiones para la memoria anual de residente de tercer año.
}

\author{
Andrea Gago ${ }^{\text {a }}$. \\ ${ }^{a}$ Residente de tercer año en Anestesiología, Reanimación y Terapéutica del Dolor. \\ Hospital Universitario Cruces. Barakaldo, Bizkaia, España \\ damgago@gmail.com
}

\section{Sr Director.}

Considerando la importancia que el periodo formativo tiene para nuestro futuro profesional he querido compartir las siguientes reflexiones con las que cerraba mi memoria anual de residente de tercer año en Anestesiología, Reanimación y Terapéutica del Dolor. Soy consciente de que a primera vista puede parecer que mi especialidad tiene matices diferenciales con respecto a otras áreas de la salud mental, pero escrupulosamente creo que tiene una estrecha relación con las mismas por diversas razones. Podría argumentar que en primer lugar mi convicción de que como médicos en general, debemos tener una concepción holística del ser humano; pero siendo franca la razón principal es que creo por sobre todas las cosas que en mi especialidad debemos tener la capacidad de brindar soporte y confort a cada paciente con la máxima empatía posible, bien sea en el paso previo del ingreso al quirófano (momento sumamente estresante), bien durante el momento "cuasi onírico" del despertar, o bien durante el tratamiento del dolor tanto agudo como crónico, donde el estado psicopatológico y emocional del paciente desarrolla un papel fundamental.

Comenzaré mi reflexión haciendo referencia a Paulo Freire (1921-1997), pedagogo y educador brasileño, quien respalda la utopía de que no hay caminos trazados de antemano, donde no se trata de perseguir un modelo perfilado de planes y racionalidad concreta, no dice a los otros lo que deben hacer. En este sentido, en su pedagogía se vive una noción abierta, sin concreciones, desarrollada ya en el propio curso del proceso educativo. Se trata de la superación de las interferencias que nos impiden hablar y escucharnos, se trata de establecer relaciones horizontales que nos permitan dialogar y aprender. Porque el educador comienza, precisamente, escuchando con toda su atención al otro, desde la íntima convicción de que el otro vale, de que el otro es capaz de aportar conocimientos. Al contrario, en toda educación de tipo vertical, que absolutiza la ignorancia del educando, lo niega como persona, lo hace "invisible”, obstaculizando la auténtica comunicación y por consiguiente la educación y el aprendizaje. 
En mi humilde opinión, el período formativo de la residencia debería al menos en parte seguir este modelo. Por lo que me parece fundamental hacernos algunas preguntas: ¿qué tipo de médicos nos estamos formando?, ¿qué tipo de profesionales queremos ser?, ¿estamos haciendo lo necesario?, ¿lo suficiente?. La respuesta a estas preguntas es compleja, no se pueden ignorar los acontecimientos sucedidos en nuestro tiempo, pues ni siquiera desde los albores de la medicina, las diversas escuelas lograron escapar a los presupuestos ideológicos de las doctrinas de cada época. Por lo que en nuestra era debemos mencionar los cambios sociodemográficos, la existencia de recursos económicos limitados (no solo insuficientes sino mal distribuidos), y los cambios en la economía sanitaria que se han sucedido. Otro factor importante lo constituye el aumento exponencial de la literatura científica y del conocimiento, con el consiguiente deseo de formar médicos enciclopedistas, con conocimientos absolutos por parte de algunas escuelas; o bien, por el contrario aquellos panegiristas de las subespecialidades. Y seguramente existan muchos aspectos importantes que no he citado, sin embargo resultan suficientes para hacer algunas consideraciones.

Nos encontramos en un hospital de referencia, terciario, con mucha carga asistencial y donde en muchas veces no se prioriza la docencia, y aún menos la investigación como parte de la formación médica. Donde aquellos que queremos formarnos de la mejor forma posible nos vemos enfrentados en algunas ocasiones (no siempre) a la burocracia y al carácter pacato del sistema. Y donde muchas veces encontrar el tiempo que deberíamos dedicar a conocer a nuestro paciente, a entenderle, a transmitirle la información de forma adecuada es una tarea titánica.

Al comenzar la residencia y con el correr de los años vamos tomando conciencia de la gran responsabilidad que conlleva nuestra noble profesión, en mi caso de la importancia que tiene la realización del acto anestésico. Resulta ardua esa formación cabal que creo estamos necesitando, en esta era de protocolos no se permite reflexionar e individualizar cada caso, muchas veces me siento como si estuviera perdiendo candidez y "humanidad", es por lo general cuando se sigue el modelo de educación vertical.

Me parece importante destacar aquí el enfoque de Formación basada en Competencias (considerado uno de los cambios más importantes en la educación sanitaria y que no pretende ser un modelo pedagógico sino un enfoque para la educación), cuyo objetivo es lograr un aprendizaje completo integrando el saber, me refiero al "saber hacer, el saber ser y el saber estar".

Espero sinceramente que este modelo se pueda implementar a la brevedad a nivel práctico en el proceso de enseñanza-aprendizaje en todos los hospitales.

Enseñar no es transferir conocimiento, sino crear las posibilidades para su producción o su construcción. Quien enseña aprende al enseñar, y quien aprende, también enseña al aprender. 